\title{
Silicon nanowire devices
}

\author{
Sung-Wook Chung, ${ }^{\text {a) }}$ Jae-Young $\mathrm{Yu}{ }^{\text {a) }}$ and James R. Heath ${ }^{\text {b) }}$ \\ UCLA Department of Chemistry and Biochemistry, Los Angeles, California 90095-1569
}

(Received 13 December 1999; accepted for publication 9 February 2000)

Transport measurements were carried out on 15-35 nm diameter silicon nanowires grown using $\mathrm{SiH}_{4}$ chemical vapor deposition via $\mathrm{Au}$ or $\mathrm{Zn}$ particle-nucleated vapor-liquid-solid growth at $440^{\circ} \mathrm{C}$. Both $\mathrm{Al}$ and $\mathrm{Ti} / \mathrm{Au}$ contacts to the wires were investigated. The wires, as produced, were essentially intrinsic, although Au nucleated wires exhibited a slightly higher conductance. Thermal treatment of the fabricated devices resulted in better electrical contacts, as well as diffusion of dopant atoms into the nanowires, and increased the nanowire conductance by as much as $10^{4}$. Three terminal devices indicate that the doping of the wires is $p$ type. (c) 2000 American Institute of Physics. [S0003-6951(00)00715-4]

Nonlithographic techniques for the fabrication of onedimensional conductors have been developed by a number of groups over the past several years. Single- and multiwall carbon nanotubes have been the focus of most of this work, but other nanowire (NW) systems, including $\mathrm{Ge},{ }^{1} \mathrm{Si}^{2}$, $\mathrm{GaAs},{ }^{3}$ and various metals ${ }^{4}$ have been prepared as well. The preparation routes for these various semiconducting NWs are generally described as vapor-liquid-solid (VLS) growth, and have been well documented. ${ }^{5-7}$ However, little in the way of electrical characterization has been reported. In fact, the question of whether or not these wires exhibit reasonable electrical conductivity remains open.

In this letter, we investigate the electrical properties of 15-35 $\mathrm{nm}$ diameter Si nanowires (SiNWs) produced via vapor-liquid-solid growth [Fig. 1(a)]. Our NW preparations are variations of techniques previously reported, ${ }^{2,8}$ and details will be presented elsewhere. ${ }^{9}$ Au nucleated wires (AuSiNWs) were grown by first evaporating $1 \mathrm{~nm}$ of $\mathrm{Au}$ onto a $\mathrm{SiO}_{2}$ wafer, which was then annealed at $450{ }^{\circ} \mathrm{C}$ under vacuum inside a quartz tube furnace. The 1-nm-thick evaporated Au typically breaks up and forms Au particles which will act as catalytic sites for SiNW growth. ${ }^{10} \mathrm{Zn}$ catalyzed $\mathrm{Si}$ nanowires ( $\mathrm{Zn}-\mathrm{SiNWs}$ ) have not been previously reported. To make them, $\mathrm{ZnCl}_{2} /$ ethanol solution was deposited on a $p$-doped Si substrate after removing the native oxide layer with HF. The substrate was heated in the quartz tube furnace at $450{ }^{\circ} \mathrm{C}$ under $5 \% \mathrm{H}_{2} / \mathrm{Ar}$ mixture at 100 Torr. For both cases, wires were grown via chemical vapor deposition (CVD) from $5 \% \mathrm{SiH}_{4} / \mathrm{He}$ gas at 100 Torr. High resolution transmission electron microscopy (HRTEM) revealed that the wires were single crystals, atomically straight, characterized by an approximately $10 \AA$ oxide coating, and were of the diameter range $14-35 \mathrm{~nm}$, and a length of 1-10 $\mu \mathrm{m} .{ }^{9}$ Devices were fabricated according literature methods ${ }^{11,12}$ and only a brief description is given here. Wires were transferred to Si wafer coated with $1500 \AA$ Axide and prepatterned with alignment markers. Several SiNWs were located using scanning electron microscopy (SEM), and standard e-beam

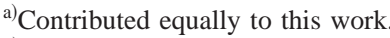

b) Author to whom correspondence should be addressed; electronic mail: heath@chem.ucla.edu lithography was utilized to write an electrode pattern that connected the NWs to larger $\left(0.027 \mathrm{~mm}^{2}\right)$ contact pads. For certain devices, a third electrode was also defined as a gate. Two different types of electrodes, either $100 \mathrm{~nm}$ Au on $5 \mathrm{~nm}$ $\mathrm{Ti}$, or 100-nm-thick Al, were then deposited using e-beam evaporation. The diameters of the wires within the assembled devices were characterized by atomic force microscopy

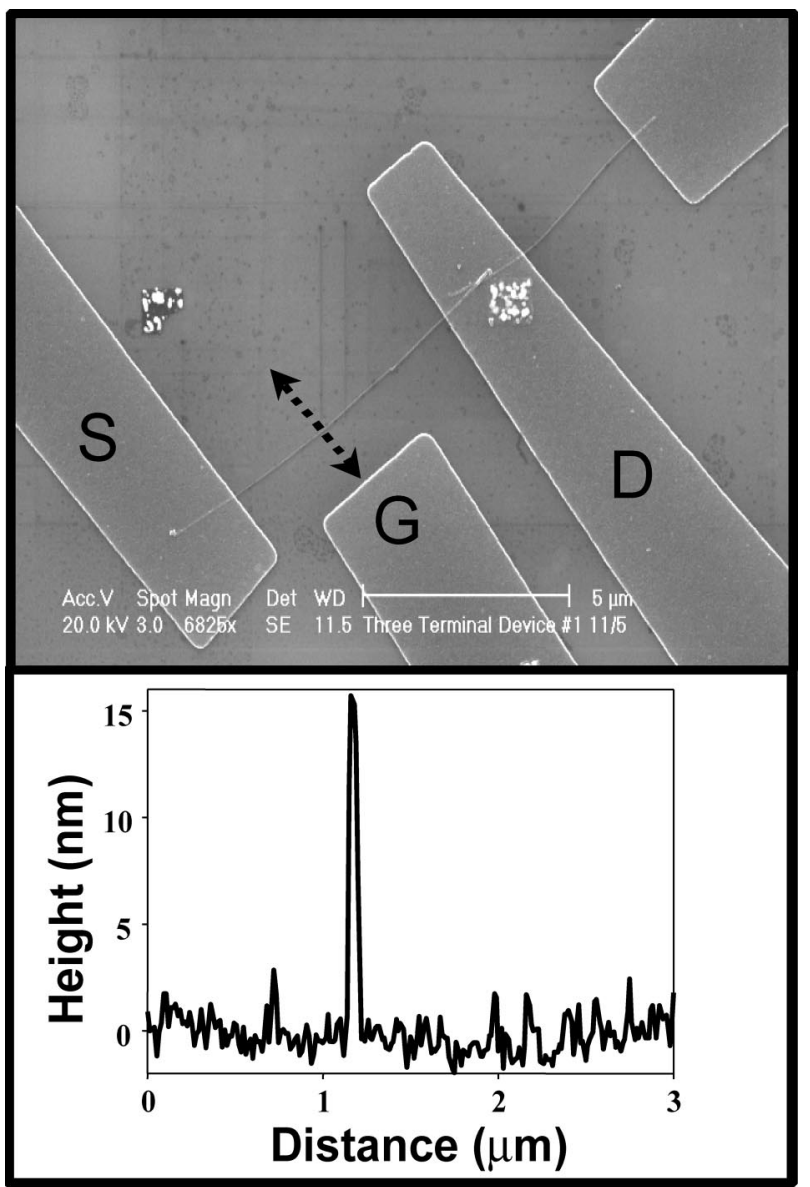

FIG. 1. (Top) SEM image of a three-terminal device, with the source (S), gate $(\mathrm{G})$, and drain (D) labeled. (Bottom) Tapping mode AFM trace of a portion of the silicon nanowire (indicated with the dashed arrow in the SEM image), revealing the diameter of the wire to be about $15 \mathrm{~nm}$. 


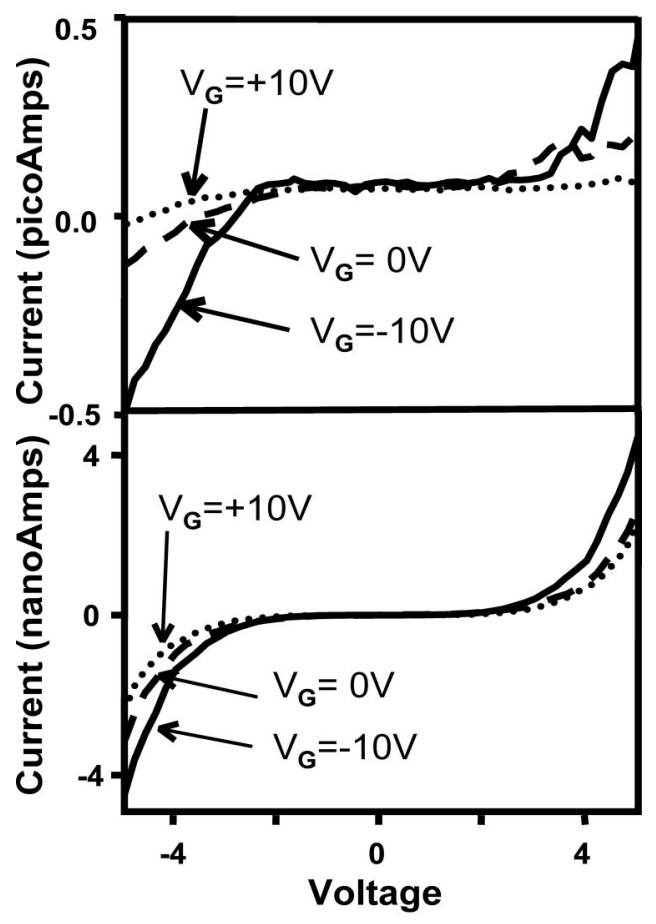

FIG. 2. Three-terminal transport measurements of an as-prepared $15 \mathrm{~nm} \mathrm{Si}$ nanowire device contacted with Al electrodes (top) and the same device after annealing at $550{ }^{\circ} \mathrm{C}$ (bottom). In both cases, the gating effect indicates p-type doping.

(AFM) [Fig. 1(b)]. Once the devices were prepared, they were interrogated using current-voltage $\left(I-V_{\text {bias }}\right)$ measurements. They could then be subsequently annealed in a vacuum oven under a flow of reducing gas $\left(5 \% \mathrm{H}_{2}\right.$ in Argon, 600 Torr) for varying temperatures and times. $I-V_{\text {bias }}$ measurements and microscopic investigation of the devices were carried out after annealing.

Our devices consist of a semiconductor connected to two metal contacts, which is the equivalent of two Schottky-type diodes connected back to back. Overall, $I-V$ characteristics of such a device should be governed by the reverse bias characteristics of Schottky diodes (i.e., transport of electrons from metal to semiconductor). ${ }^{13}$ All our devices, prior to annealing, show $I-V$ characteristics of back-to-back diodes. Both types of SiNWs were insulators, but the Au-SiNWs exhibited currents in the range of tens of picoAmps (pA) at $V_{\text {bias }}=4 \mathrm{~V}$, while Zn-SiNWs exhibited currents of only about $1 \mathrm{pA}$ at $V_{\text {bias }}=4 \mathrm{~V}$. When Zn-SiNWs, contacted to Al electrodes, were annealed at $550^{\circ} \mathrm{C}$ for $15 \mathrm{~min}$, the current at $V_{\text {bias }}=4 \mathrm{~V}$ was observed to increase by $>10^{3}$. Threeterminal measurements [Figs. 2(a) and 2(b)] indicated that the shape of the $I-V$ curve does not significantly change for the annealed device, and that the NWs are $p$ doped before and after annealing, although after annealing the doping level is a little higher. We therefore conclude that the increased conductance of the $\mathrm{Zn}$-SiNW devices upon annealing at $550^{\circ} \mathrm{C}$ is largely attributable to better electrode/ $\mathrm{NW}$ contacts.

$I-V$ characteristics of two-terminal Au-SiNW devices contacted with Ti/Au electrodes, both "as-prepared" and annealed, are shown in Fig. 3. These devices were annealed at $750{ }^{\circ} \mathrm{C}$ for $30 \mathrm{~min}$. The annealing leads to an increase in current (at $V_{\text {bias }}=4 \mathrm{~V}$ ) of approximately $10^{4}$. In this case, the this picture and they are currently in progress.
Downloaded 19 May 2006 to 131.215 .225 .175 . Redistribution subject to AlP license or copyright, see http://apl.aip.org/app

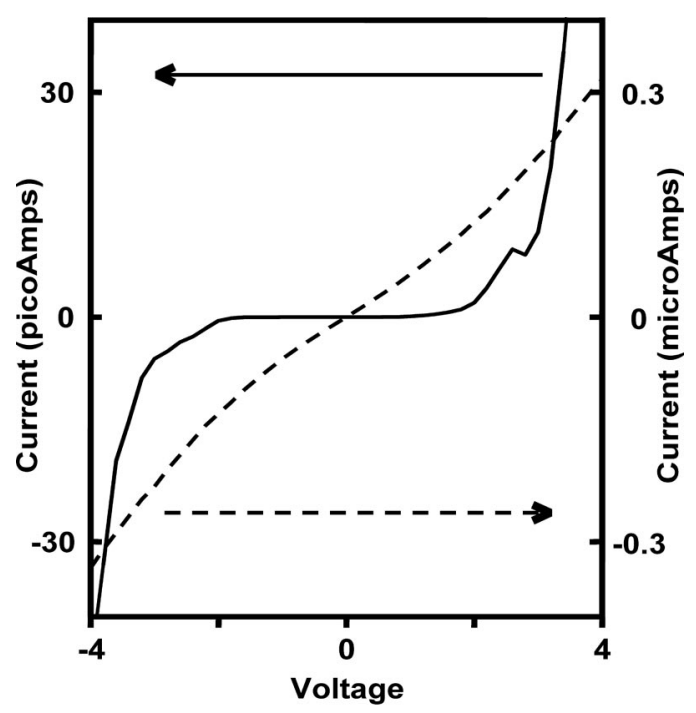

FIG. 3. $I-V$ characteristics of Au-nucleated Si nanowires contacted with $\mathrm{Ti} / \mathrm{Au}$ electrodes, before (solid line, current axis on left) and after (dashed line, current axis on right) thermal treatment $\left(750^{\circ} \mathrm{C}, 1 \mathrm{~h}\right)$. After annealing the wire exhibits metallic-like conductance, indicating that the wire has been heavily doped.

annealing of the Au-SiNWs changes the shape of the $I-V$ curve, so that the annealed device exhibits metallic-like conductance (nonzero slope at $V_{\text {bias }}=0 \mathrm{~V}$ ). No gating effect was observed for the annealed device, up to $V_{G}= \pm 40 \mathrm{~V}$. The diffusion coefficient of $\mathrm{Au}$ in $\mathrm{Si}$ at $750-800^{\circ} \mathrm{C}$ is large enough to heavily dope the entire wire with the Au. Furthermore, at $750^{\circ} \mathrm{C}$ the $\mathrm{Si} \mathrm{NW}$ surface can react with Ti to form $\mathrm{TiSi}_{2}$ which can lower the contact resistance. We conclude that the increased conductance of the Au-SiNWs upon annealing at $750^{\circ} \mathrm{C}$ is the result of both doping and decreased contact resistance.

The effect of the annealing on the transport properties of the wires may be qualitatively understood if we assume that all devices are characterized by ohmic contacts and uniform charge density. In that case, the upper limit for current density is given by

$$
J=q \mu_{n} n E+q \mu_{p} p E,
$$

where $J$ is current density, $q$ is the electron charge, $\mu_{n}$ is electron mobility, $\mu_{p}$ is hole mobility, $n$ is electron concentration, $p$ is hole concentration, and $E$ is electric field. The field inside the wire is simply $E=V_{\text {applied }} / d$ where $d$ is the length of wire between the electrodes. For intrinsic silicon, $\mu_{n}$ is $1500 \mathrm{~cm}^{2} / \mathrm{V} \mathrm{s}, \mu_{p}$ is $600 \mathrm{~cm}^{2} / \mathrm{V} \mathrm{s}, n$ and $p$ are 4.58 $\times 10^{9} \mathrm{~cm}^{-3}$. For a $1-\mu \mathrm{m}$-long intrinisic wire at $V_{\text {bias }}=4 \mathrm{~V}$, the current density is $6.16 \times 10^{-6} \mathrm{~A} / \mathrm{cm}^{2}$, which translates to $<1 \mathrm{pA}$ for a $20 \mathrm{~nm}$ diameter SiNW. This calculation implies that our SiNWs, even prior to annealing, are doped.

$\mathrm{Au}$ (and $\mathrm{Zn}$ ) atoms in silicon can serve as both deep scattering centers (which decrease the carrier mobility) and $p$-type dopants. It therefore was not initially clear whether the conductivity of these SiNWs would increase or decrease upon $\mathrm{Au}$ (or $\mathrm{Zn}$ ) doping. However, the data presented here indicate that the increase of the majority carrier concentration greatly offsets the decrease of the carrier mobilities. Hall measurements of SiNW devices will do much to quantify this picture and they are currently in progress. 
The authors would like to thank Professor Paul McEuen for helpful discussions. This work was funded by the ONR (Grant No. N00014-98-1-0422) and DARPA.

${ }^{1}$ J. R. Heath and F. K. LeGoues, Chem. Phys. Lett. 208, 263 (1993).

${ }^{2}$ A. M. Morales and C. M. Lieber, Science 279, 208 (1998).

${ }^{3}$ T. J. Trentler, K. M. Hickman, S. C. Goel, A. M. Viano, P. C. Gibbons, and W. E. Buhro, Science 270, 1791 (1995).

${ }^{4}$ D. N. Davydov, J. Haruyama, D. Routkevitch, B. W. Statt, D. Eliis, M. Moskovits, and J. M. Xu, Phys. Rev. B 57, 13550 (1998).

${ }^{5}$ R. S. Wagner and W. C. Ellis, Appl. Phys. Lett. 4, 89 (1965).
${ }^{6}$ E. I. Givargizov, J. Chem. Phys. 31, 20 (1975)

${ }^{7}$ E. I. Givargizov, Curr. Top. Mater. Sci. 1, 79 (1978).

${ }^{8}$ J. Westwater, D. P. Gosain, S. Tomiya, S. Usui, and H. Ruda, J. Vac. Sci. Technol. B 15, 554 (1997).

${ }^{9}$ J.-Y. Yu, S.-W. Chung, and J. R. Heath (unpublished).

${ }^{10}$ N. Ozaki, Y. Ohno, and S. Takeda, Appl. Phys. Lett. 73, 3700 (1998).

${ }^{11}$ M. Bockrath, D. H. Cobden, P. L. McEuen, N. G. Chopra, A. Zettl, A. Thess, and R. E. Smalley, Science 275, 1922 (1997).

${ }^{12}$ S. J. Tans, A. R. M. Vershueren, and C. Dekker, Nature (London) 393, 49 (1998).

${ }^{13}$ Physics of Semiconductor Devices, 2nd ed., edited by S. M. Sze (Wiley, New York, 1981). 